\title{
The Clinic and the Journal: Respecting the past and welcoming the future
}

This year is the 100th anniversary of the founding of Cleveland Clinic. While CCJM is most emphatically not an "in-house" journal, a centennial does warrant some selfbackslapping and, as with all anniversaries, it is an opportunity to reflect on where we have come from and where we are going.

The concept of the multidisciplinary Clinic was born from experiences shared by Cleveland physicians at field hospitals in World War I. Three surgeons (Drs. Frank Bunts, George Crile, and William Lower) and one internist (Dr. John Phillips) established a group practice in 1921, a hospital in 1924, and shortly thereafter a dedicated research facility. The last I find most striking - that a group of clinicians, even while struggling to launch and gather acceptance for their novel practice in the community, would feel strongly enough about the need to advance and contribute knowledge that they would embark on such an effort. The Mayo brothers, who established their clinic in 1889 , also recognized the value of linking medical practice with clinical investigationbench to bedside.

In the current issue, we present two historical perspectives written by former editors of the Journal. Dr. John Clough, historian of all things Cleveland Clinic, is also the former chairman of rheumatology at the Clinic and a lupus investigator. John briefly summarizes the growth of the Clinic, reflecting on his own 50-plus years here in research, clinical practice, and administration. I succeeded John as editor in chief of the Journal in 2005.

Dr. James Taylor was editor in chief before John, in 1982-1992, and he is known nationally for his writing and experience in allergic patch testing. He reflects on the history of the Journal up to the present, noting challenges medical publications face. Thinking about these challenges segues naturally into reflections on the future.

Medical publications face rising costs, and print publications are especially challenged. Historically, costs have been offset by advertisements and, for some journals, by subscription fees. For CCJM, the Clinic has underwritten much of the cost, a vivid (and costly) demonstration of the institutional leadership's commitment, especially that of Dr. Tom Mihaljevic (President and CEO) and Dr. Jamie Stoller (Chairman of the Education Institute) to postgraduate medical education with the goal of improving medical care. As pressures increase on journals to go digital, and as "in the moment" social media seemingly dominate the lives of an entire generation, we have maintained our belief in the value of the printed format for the information that we present-although we additionally post all of our material online free of charge. And we continue to provide free CME credit for articles appearing in the Journal.

But it is our authors, our editorial staff, and our peer reviewers who make CCJM what it is. I wish to update you on some upcoming changes. Kristi Thomsen, who has been our Executive Editor since she took the reins from Phil Canuto in 2014, is 


\section{CONTINUED FROM PAGE 6}

retiring. We thought Phil was irreplaceable, but Kristi has ably managed the flow of manuscripts and has helped us deal with key transitions in our online publishing. Kristi will indeed be missed. And the major in-house regret is that there will be no in-person retirement party.

Taking on the role and tasks of Executive Editor will be Mary Cusick. Mary has been with the Clinic since 2008 in several editorial and publication roles and with CCJM since 2015. She has overseen special projects and most recently has been our linchpin in the collation and editing of content on our COVID-19 Curbside Consult online postings. She also gets no party, just a list of manuscripts that I am late in reviewing.

Lastly, this month we are excited to introduce the first issue of the United Kingdom edition of CCJM. Intended to showcase the educational component of our presence at Cleveland Clinic London, CCJM-UK will include material from CCJM as well as some additional material targeting our international readers.

Professor Olaf Wendler, MD, PhD, will serve as Chief Editor of CCJM-UK. Dr. Wendler is the new Chair of the Heart, Vascular, and Thoracic Institute at Cleveland Clinic London. He is a Fellow of the Royal College of Surgeons and Professor of Cardiac Surgery at King's College London. I plan to take advantage of his unique expertise in complex valvular heart disease, so you can look forward to hearing from him in the future.

We at CCJM join you all in hoping for a peaceful and safer 2021.

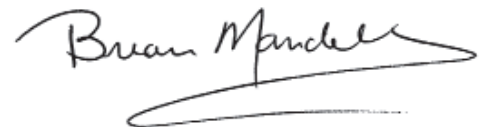

BRIAN F. MANDELL, MD, PhD Editor in Chief 